\title{
A new seamless digital 1:500 000 scale geological map of Greenland
}

\author{
Mikael Pedersen, Willy L. Weng, Nynke Keulen and Thomas F. Kokfelt
}

For around 40 years, the Geological Survey of Greenland (GGU) and later the Geological Survey of Denmark and Greenland (GEUS) conducted systematic geological overview mapping of Greenland, leading to the production of 14 printed map sheets on a scale of 1:500 000 which covers the entire country (Fig. 1). The mapping was completed in 1999 and the map sheets were published between 1971 and 2004. Revised 2 nd editions of two of the sheets have been published (Table 1).

As a result of the development of the Internet, the publication platform for geological maps has increasingly moved from traditional paper sheets to digital publications for most geological surveys worldwide. This tendency has changed the requirements to the underlying production, storage and publication platforms for map data. For the same reason, it has over the past decade been a strategy of GEUS to bring the 1:500 000 geological maps of Greenland together as a seamless, digital product with a homogeneous legend. This has been further motivated by the increasing number of Geographic Information System (GIS) and web applications to which such a map would provide a valuable background, as well as to many international projects such as OneGeology. The harmonisation of the geological maps was carried out by a project team at GEUS comprising both geological and GIS expertise. The first version of the new seamless map was finished in 2012 and will be released in various web applications in 2013.

\section{Digitisation}

The production of a seamless, digital product makes new demands on the underlying map data. Most importantly, all data have to be in vector form in a GIS environment. Only the three most recent of the 14 original map sheets mentioned above were produced digitally (sheets 6,9, and 11; Fig. 1, Table 1). As part of the project Thematic maps and data of North and Northeast Greenland: geology, mineral occurrences and hydrocarbons (Mikkelsen et al. 2005; Christoffersen \& Jepsen 2007) four of the printed map sheets (sheets $7,8,10$ and 12) were vectorised. Of the remaining seven sheets, two sheets ( 1 and 3 ) were up for revision, and new editions were produced digitally in 2007 and 2010. The last five (sheets 2, 4, 5,13 and 14) were vectorised in order to create full digital coverage.

The vectorisation was done from scanned versions of the published maps. In this process, the geological information was taken from the maps and integrated with the best available topographic base-map data, which in most cases were photogrammetric data derived from 1:150 000 aerial photographs (based on aerotriangulations of varying quality). Some of the topography from printed maps was taken from G/250 Vektor data from the Danish Geodata Agency and used in map sheets 1, 4 and 5. Due to the nature of the mapping technique and the geodetic control, the old geological paper maps had a much better local than absolute accuracy: the geometric relations between a geological feature and

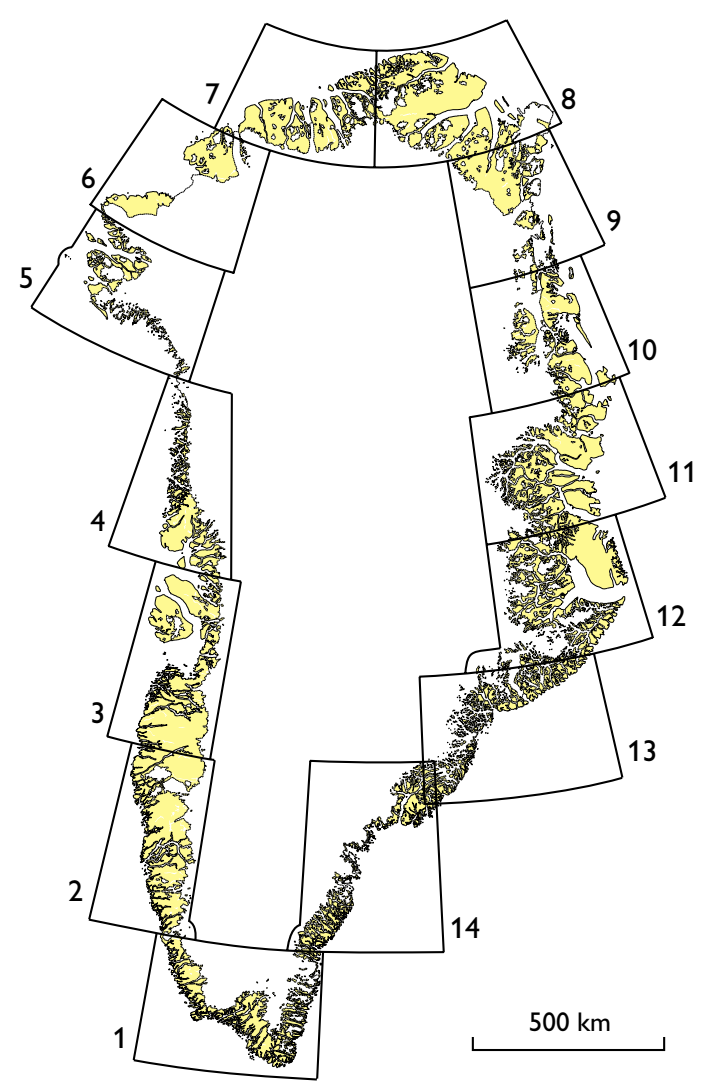

Fig. 1. Index map of Greenland showing the boundaries of the 14 geological map sheets on a scale of 1:500 000 covering Greenland. 
Table 1. Data on the Greenlandic bedrock maps 1:500 000

\begin{tabular}{|c|c|c|c|c|c|c|}
\hline No & Name & Compilers & Published & Edition & $\begin{array}{l}\text { Cartographic } \\
\text { technique }\end{array}$ & $\begin{array}{l}\text { Topography } \\
\text { source }\end{array}$ \\
\hline 1 & Sydgrønland & A.A. Garde & 2007 & 2 & Digital & Mixed \\
\hline 2 & Frederikshåb Isblink - Søndre Strømfjord & J.H.Allaart & 1982 & & Analog & Photogr. \\
\hline 3 & Søndre Strømfjord - Nuussuaq & A.A. Garde \& M. Marker & 2010 & 2 & Digital & Photogr. \\
\hline 4 & Upernavik Isfjord & J.C. Escher & 1985 & & Analog & Paper map \\
\hline 5 & Thule & P.R. Dawes & 1991 & & Analog & Paper map \\
\hline 6 & Humboldt Gletscher & P.R. Dawes \& A.A. Garde & 2004 & & Digital & Photogr. \\
\hline 7 & Nyeboe Land & N. Henriksen & 1989 & & Analog (D) & Photogr. \\
\hline 8 & Peary Land & H.-J. Bengaard \& N. Henriksen & 1986 & & Analog (D) & Photogr. \\
\hline 9 & Lambert Land & H.F. Jepsen & 2000 & & Digital & Photogr. \\
\hline 10 & Dove Bugt & N. Henriksen & 1997 & & Analog (D) & Photogr. \\
\hline 11 & Kong Oscar Fjord & J.C. Escher & 2001 & & Digital & Photogr. \\
\hline 12 & Scoresby Sund & H.-J. Bengaard \& N. Henriksen & 1984 & & Analog (D) & Photogr. \\
\hline 13 & Kangerdlugssuaq & J.S. Myers, P.R. Dawes \& T.F.D. Nielsen & 1988 & & Analog & Photogr. \\
\hline 14 & Skjoldungen & J.C. Escher & 1990 & & Analog & Photogr. \\
\hline
\end{tabular}

D: vectorised as a part of the project Thematic maps and data of North and Northeast Greenland (Mikkelsen et al. 2005; Christoffersen \& Jepsen 2007)

the nearby topographic features, such as shore lines and rivers, are usually correct even if the location of such features is quite wrong (as indicated for example by the geographic grid). During vectorisation in the GIS environment, it was therefore constantly necessary to shift the scanned geological map in order to fit the printed map topography to the new digital topography, which in some cases was rather different from that on the printed map.

The digitisation included boundaries between exposed geological units and structural elements, all of which were attributed with type and source information. Subsequent to the vectorisation, polygons were formed and encoded according to their geological type. As the GIS data were stored in a single seamless database, geometric ambiguities across map-sheet boundaries had to be corrected.

The geometric quality of the final map varies substantially. In areas with well-defined topographic features and the best possible photogrammetry, mean errors around $50 \mathrm{~m}$ can be expected. However, in areas where topography from paper maps was used as reference during digitisation, errors

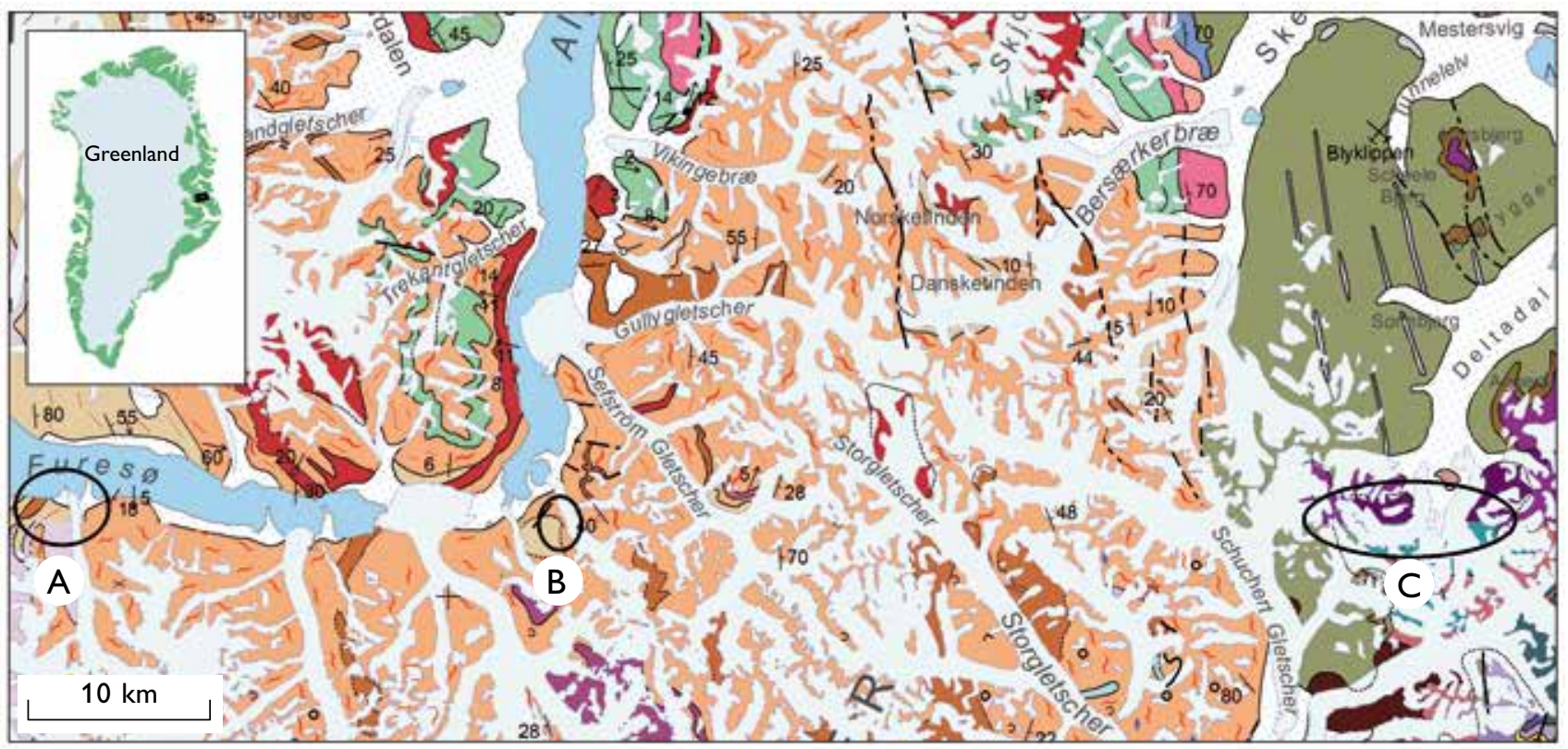

Fig. 2. Geological map of the Mestersvig area in central East Greenland. A, C: examples of how mapping inconsistencies between two printed map sheets are displayed, where the same unit is shown with different colours across the former map-sheet boundary. $\mathbf{B}$ : an example of a geometrical problem where a boundary between two units shows a 'jump'. These small inconsistencies remain on the new digital map. 

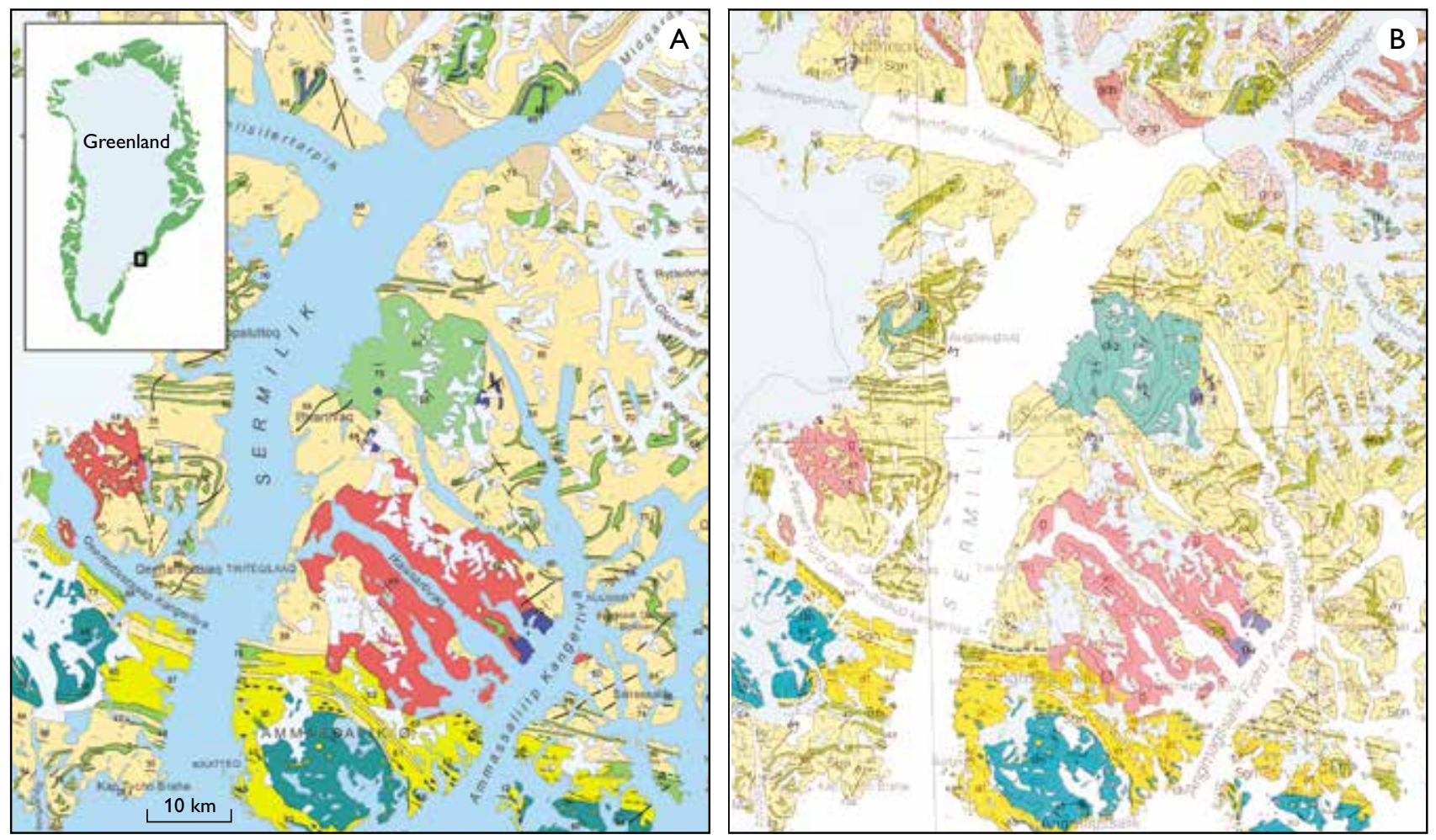

Fig. 3. The colours on the digital map follow the colour scheme of the original 1:500 000 scale maps, but have been updated to modern standards where necessary. An example from South-East Greenland (map sheet 14). A: The new digital map. B: The same area on the printed version that was published in 1990 (Table 1).

are probably around $250 \mathrm{~m}$. The position of the ice margin shown on the paper maps is even worse. In the Baffin Bay region for example, the ice-margin position in the 1950s is used.

Another important part of the geographic data set is the place names. Although not all of the place names on the printed maps have been digitised yet, the current data set already contains more than 2500 place names.

The concept of map scale also remains when data are being used digitally. The target 1:500 000 scale has governed the selection of features and their degree of detail; it also applies to the base topography that was duly generalised, typically from 1:100 000 originals.

\section{Geological harmonisation}

The 14 map sheets that form the basis of the new seamless 1:500 000 scale map were published between 1982 and 2010 . The original maps all have their own way of presenting the geology, depending on the map compilers and the individual mapping geologists. The maps vary greatly in degree of detail reflecting the amount of time spent during the original mapping, and the availability of helicopter support in the different areas. Furthermore, the maps show an evolution in the understanding of the geology, and changes in mapping philosophy from older to younger maps.

An important issue was to implement a uniform geological nomenclature to the entire map, so that a single, harmonised legend for all of Greenland could be developed. Since no geological remapping was done, the level of detail displayed in different areas remains uneven. Therefore, boundaries between mapping areas of individual mapping parties, both within former map areas and across former map boundaries, to a large extent remain visible. An example of this is shown in Fig. 2.

The homogenised legend for the Thematic maps of North and Northeast Greenland at 1:250 000 (Christoffersen \& Jepsen 2007) was used used as a basis for further harmonisation; the harmonisation process was started by combining the adjacent four map sheets (sheet 5, 6, 12 and 13), where similar geological units occur, into a common legend.

The north-western, northern, north-eastern and eastern parts of Greenland largely consist of Palaeoproterozoic to Paleogene sedimentary basins. The sediments are divided into groups, formations and members described in variable, although generally high degrees of detail. The western, southern and south-eastern parts of Greenland mainly consist of metamorphosed Archaean and Palaeoproterozoic 
basement rocks. In line with the original, printed 1:500 000 maps, the rock units in these parts of Greenland are mainly divided by their age and petrography. In cases where Archaean rocks have undergone later reworking, e.g. Archaean gneisses deformed and metamorphosed in the Palaeoproterozoic, the entry in the legend is placed under the time of formation and not under the time of reworking, as on the original paper map sheets. The legends of most of the printed map sheets contain a number of rock types with generic names such as orthogneiss, amphibolite, mica schist, granite and ultramafic rocks. These units have been pooled into broader units that cover all of the corresponding rock types of similar age. However, if the original map sheet showed similar rock units with special features as separate types (e.g. the welldescribed, pyroxene-bearing Ilivertalik granite), these have been retained in order not to loose information compared with the original map sheets.

\section{Legend}

The link between geological features on a digital geological map and the corresponding legend is ensured by the use of codes. Each polygon on the map has a code, which is translated into a colour and a descriptive text by the GIS program. In the course of geological harmonisation, the codes from the various input maps were translated into a new, homogeneous encoding scheme so that, e.g. an 'undifferentiated gneiss' in one area got the same code as a corresponding unit in another area. This work was carried out using a combination of translation tables and Python scripts, and resulted in a total list of 443 unique codes each representing a geological unit.

The geological units were subsequently compiled in a legend organised by age and region. Rock units that belong to a supergroup, a sedimentary basin, an igneous province or a metamorphic complex have been grouped together, even if they cover more than one time period. The grouping by age starts with Quaternary deposits and ends with Eoarchaean rocks of the Isua complex. Each original 1:500 000 map sheet legend had its own style, therefore a harmonisation of rock descriptions was also necessary. Where the nomenclatures are obsolete, rock names have been adopted to modern nomenclature. We mainly followed the principles by the British Geological Survey (Gillespie \& Styles 1999; Hallsworth \& Knox 1999; Robertson 1999).

A data set containing as many different feature types as described requires careful symbolisation. The one currently used tries to stay as close as possible to the tradition of the printed maps of GGU and GEUS. However, some colours mainly for igneous rocks - have been adapted to colours that are more common on modern maps (Fig. 3).

The new digital compilation is to a large degree intended for viewing on a computer screen. For that reason, the first version of the new map has only been assigned RGB colours. Another colour scheme for map-sheet printing using CMYK colours will be developed at a later stage.

\section{Publication platforms}

Compared to a printed map, a digital geological map has more potential applications. First of all, it is well suited for GIS work where users can zoom in on areas of interest and examine the geology e.g. by clicking on geological features and receive detailed information from the underlying databases. The new seamless map has been integrated in such a Web-GIS application which can be found at http://data. geus.dk/map2/geogreen.

The seamless map is furthermore an important GEUS contribution to the global OneGeology portal (http://portal.onegeology.org). This portal aims to put geological maps from all countries in the world together on a scale of 1:1 million or better, by using distributed web map services (WMS). The geological map of Greenland on this portal is currently a 1:2 500000 scale map. The new 1:500 000 map will fulfil GEUS' participation in this important international initiative.

\section{References}

Christoffersen, M. \& Jepsen, H.F. 2007: Geological maps of North and North-East Greenland 1:250 000. Copenhagen: Geological Survey of Denmark and Greenland.

Gillespie, M.R. \& Styles, M.T. 1999: BGS rock classification scheme 1. Classification of igneous rocks. British Geological Survey Research Report RR 99-06, 52 pp.

Hallsworth, C.R. \& Knox, R.W.O'B. 1999: BGS rock classification scheme. Classification of sediments and sedimentary rocks. British Geological Survey Research Report RR 99-03, 44 pp.

Mikkelsen, N., Jepsen, H.F., Ineson, J.R., Piasecki, S., von Platen-Hallermund, F., Schøjth, F., Thomassen, B. \& Weng, W.L. 2005: Thematic maps and data of North and Northeast Greenland: geology, mineral occurrences and hydrocarbons. Danmarks og Grønlands Geologiske Undersøgelse Rapport 2005/28, 56 pp.

Robertson, S. 1999: BGS rock classification scheme 2. Classification of metamorphic rocks. British Geological Survey Research Report RR 99-02, 24 pp.

Authors' address

Geological Survey of Denmark and Greenland, Øster Voldgade 10,DK-1350 Copenhagen K, Denmark; E-mail: mp@geus.dk 